\title{
Impacts of long-term increase in silicon concentration on diatom blooms in Lake Kasumigaura, Japan
}

\author{
Hiroyuki Arai* ${ }^{*}$ and Takehiko Fukushima \\ Graduate School of Life and Environmental Sciences, University of Tsukuba, Tsukuba, Ibaraki 305-8572, Japan
}

Received 28 February 2014; Accepted 5 August 2014

\begin{abstract}
In the eutrophic Lake Kasumigaura in Japan, a trend of dissolved Si (DSi) concentration was detected over the last three decades, probably caused by the DSi release enhanced by an increase in sediment resuspension for the same period (Arai et al., Limnol., 13, 81-95, 2012). The present study described the long-term trends of the magnitude and seasonality of diatom blooms in the lake during 1981-2010 using the database and assessed the influencing factors for the trends by the numerical simulation of DSi and diatoms. The box model was developed based on the lake budgets (inflow, outflow, release and sedimentation) and the simple diatom growth model depending on DSi, temperature and light condition. As results, database analysis detected a long-term trend of increasing diatom abundance and a shift of blooming season from spring and autumn to the winter-spring period. Si could be regarded as a main nutrient factor limiting diatom growth by analyzing N:P:Si ratios. Our model simulation relatively well-reproduced the increasing trend and the shift of seasonality of DSi and diatoms, even though peaks of diatom blooms were underestimated in some years. Among input variables, the concentration of resuspended sediments radically increased. The model simulation with the input variables or parameters changed suggested as follows: (1) the recent DSi release from resuspended sediments enhanced diatom abundance and (2) the degradation of light condition caused by resuspension affected the shift of blooming season. These findings implicate the significance of the interactions between sediments and water to phytoplankton blooms.
\end{abstract}

Key words: Silicon / diatoms / release / model simulation / Lake Kasumigaura

\section{Introduction}

Diatoms, the most abundant phytoplankton on Earth, play an important role in the global primary production and marine biogeochemical cycles, especially in the sequestration of carbon dioxide from the atmosphere via the biological pump (Schelske, 1999; Conley et al., 2006). They take up silicon ( $\mathrm{Si}$ ) as silicate, which they mainly incorporate as amorphous silica in their frustules. Therefore, Si dynamics could affect the phytoplankton dominance, food web and biogeochemical cycling in both marine and freshwater ecosystems (Kristiansen and Hoell, 2002; Li et al., 2007).

A decreasing trend of dissolved $\mathrm{Si}$ (DSi) loads from land to sea was observed globally during the last few decades, probably caused by human activities such as dam construction and nitrogen $(\mathrm{N})$ and phosphorus $(\mathrm{P})$

\footnotetext{
*Corresponding author: arai30312@ies.life.tsukuba.ac.jp $\dagger$ Research Fellow of the Japan Society for the Promotion of Science
}

emission (Humborg et al., 1997; Teodoru et al., 2006). Following the DSi trapping by diatoms in eutrophicated stagnant waters, consequent changes in the N:P:Si stoichiometric ratio of the river water flowing into the coastal sea may be advantageous to nonsiliceous algae (potentially causing harmful algal blooms) but disadvantageous to diatoms (Officer and Ryther, 1980; Humborg et al., 1997; Ittekkot et al., 2000). For instance, Humborg et al. (1997) showed that the decrease in the DSi load of the influent rivers and the consequent changes in the $\mathrm{Si} / \mathrm{N}$ ratio in the Black Sea seem to be responsible for dramatic shifts in the composition of phytoplankton species from diatoms to coccolithophores and flagellates in the sea.

In Japan, Harashima et al. (2006) described the sensitivity of the ecosystem to Si processes in the aquatic continuum composed of Lake Biwa, the Yodo River and the Seto Inland Sea. Koszelnik and Tomaszek (2008) discussed the role of the N:P:Si ratio not only in marine environments but also in freshwater ecosystems such as natural lakes. The regular monitoring of the DSi or N:P:Si ratio is thus important, especially in lakes and estuaries 


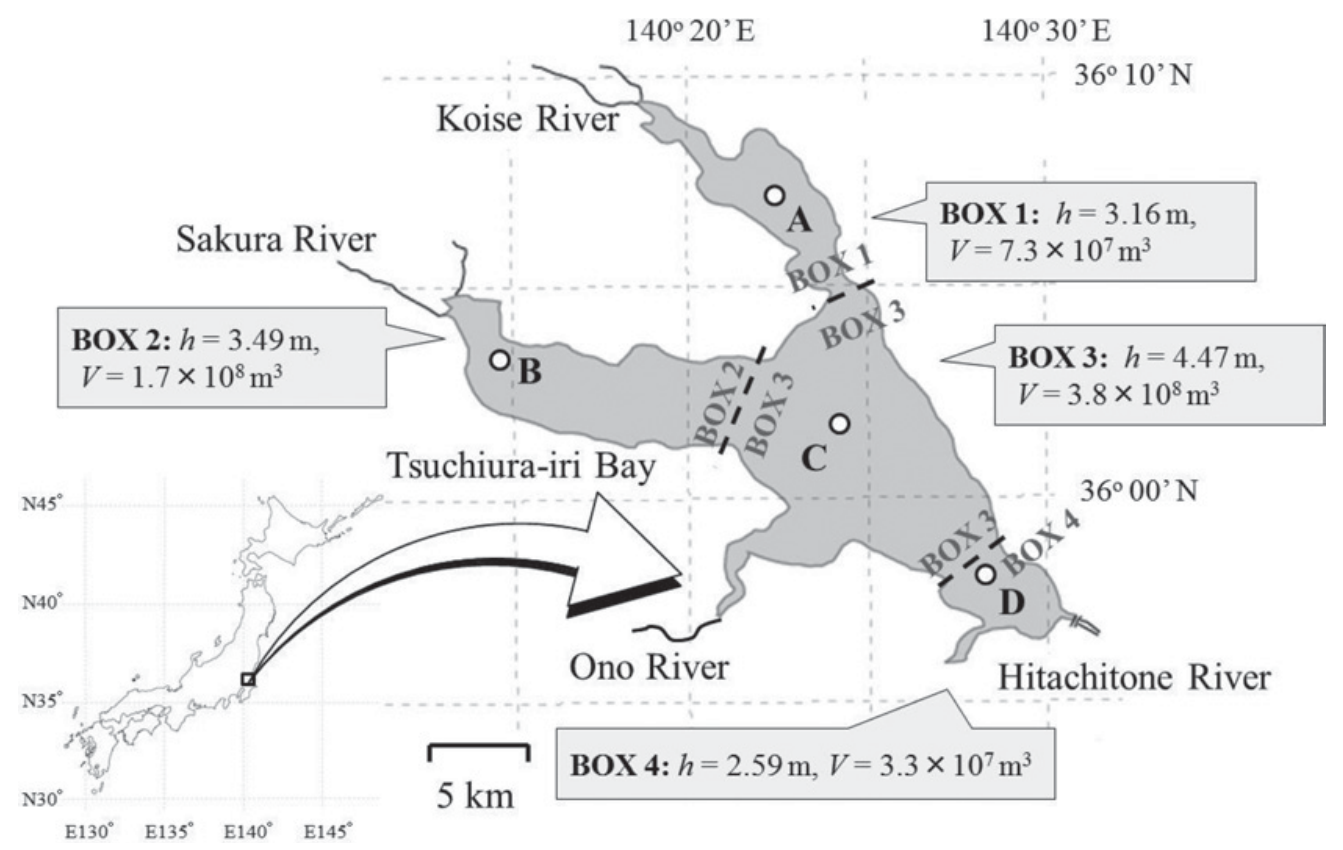

Fig. 1. Observation sites in Lake Kasumigaura and box parameters on the model.

subjected to intense human activities. Several limnological studies suggested that the long-term changes in DSi and diatom blooms can be explained by a shift in a limiting nutrient for diatoms due to $\mathrm{P}$ emissions or its constraint (Schelske, 1985; Barbiero et al., 2002; Köhler et al., 2005), but here are few detailed assessments of the effects of Si dynamics on freshwater ecosystems, mainly due to the paucity of Si monitoring relative to $\mathrm{N}$ and $\mathrm{P}$ (Foundation of River and Watershed Environment Management, 2007).

Several studies developed a simple mechanistic model for simulating diatom abundance which incorporates a growth function determined by the availability of $\mathrm{Si}$ in lakes (e.g., Ferris and Lehman, 2007) and rivers (e.g., Bormans and Webster, 1999; Callies et al., 2008). Ferris and Lehman (2007) reported that the spring development of diatoms and the DSi concentration in Ford Lake, MI, USA were markedly different in 2004 from 2005 and 2006. Their model simulations implicated hydrologic differences among the years as the cause of the differential success of the diatom populations in the spring of each year. However, few modelling studies have assessed long-term changes in DSi concentration and diatom abundance.

In the eutrophic Lake Kasumigaura in Japan, a trend of increasing DSi concentration was detected over the last three decades (mean DSi concentrations measured by a colorimetric method during the 1980s and the 2000s were 1.3 and $4.0 \mathrm{mg} . \mathrm{L}^{-1}$, respectively; Arai et al., 2012). On the other hand, considerable increase in suspended solids (SS) was also observed during the same period, due mainly to the resuspension of bottom sediments (Seki et al., 2006). Although the cause of the increase in resuspension was unclear, Seki et al. (2006) indicated that the sediment properties might become susceptible to resuspending by a wind, such as an increase in water content and a decrease in organic content. Arai et al. (2012) suggested that the increase in sediment resuspension enhanced DSi release, approximately explaining the latest DSi increase, based on the laboratory experiments in which surface sediments were stirred in lake waters. Such a trend is rare in the world; in addition, Lake Kasumigaura has a valuable database of phytoplankton and other water qualities. The purposes of the present study were threefold: (1) to detect the long-term trend of diatom blooms in Lake Kasumigaura during the last three decades, (2) to characterize the relationships between diatom abundance and water qualities, especially focusing on the DSi concentration, and (3) to assess the factors influencing the trend, focusing on the recent sediment resuspension attributing the DSi increase, using a simple box model.

\section{Materials and methods}

\section{Study area}

Lake Kasumigaura is the second largest shallow lake in Japan, located in Ibaraki Prefecture, approximately $50 \mathrm{~km}$ northeast of Tokyo. The lake has a group of contiguous basins: Nishiura, Kitaura and two others (the Hitachitone River and Sotonasakaura). In this study, "Lake Kasumigaura" indicates only Nishiura (Fig. 1). It has a surface area of $171.5 \mathrm{~km}^{2}$, a mean depth of $4 \mathrm{~m}$, and a maximum depth of $7.3 \mathrm{~m}$. Mean water retention time is about 200 days. The lake is so shallow that vertical stratification is easily destroyed by a moderately strong wind (Muraoka and Fukushima, 1986). The lake has two large bays: Takahama-iri and Tsuchiura-iri. The Koise, Sakura and Ono Rivers are the main influent rivers. Water tends to flow through the lake from the northwest to the southeast, to the effluent Hitachitone River. Its 1426- $\mathrm{km}^{2}$ 
catchment area (excluding the lake area) is about $30 \%$ forests, $25 \%$ paddy fields, $25 \%$ ploughed fields, $10 \%$ residential and about $10 \%$ others. The major surface geology in the catchment is loam. The climate of the area is similar to other regions on the Pacific side of Japan with the annual average air temperature of about $14{ }^{\circ} \mathrm{C}$ and an annual precipitation of $1250 \mathrm{~mm}$. The lake was turned from a brackish into a freshwater lake 5 years after a floodgate to the Pacific Ocean was implemented in 1963.

The lake is well known for eutrophication. Although the nutrient loads through the influent rivers were reduced due to intensive management of the basins, nutrient concentrations in the lake are still very high and the lake is still considered hypereutrophic. Due to the shallowness, processes such as sediment-water exchanges play a great role in nutrient dynamics in the lake (Havens et al., 2001; Fukushima et al., 2010). From the late 1990s to the mid2000s, considerable increases in turbidity were also observed in the lake and the resuspension of bottom sediments was suggested, possibly causing the decline in primary production and the increase in $\mathrm{P}$ concentrations (Fukushima et al., 2005; Seki et al., 2006).

\section{Field data}

The database of monthly water quality and phytoplankton abundance was obtained by the National Institute for Environmental Studies (NIES) from 1981 to 2010 (four stations in Lake Kasumigaura; Fig. 1). Surface waters were collected and filtered through $0.45-\mu \mathrm{m}$ glass-fiber filter for the analysis of the DSi concentrations by the inductively coupled plasma (ICP) method. The following nutrients at site $\mathrm{C}$ were used for analyzing the nutrient limitations for diatoms: dissolved inorganic nitrogen (DIN; $\mathrm{NH}_{4}-\mathrm{N}+\mathrm{NO}_{2}-\mathrm{N}+\mathrm{NO}_{3}-\mathrm{N}$ ) and phosphorus (DIP; solely $\mathrm{PO}_{4}-\mathrm{P}$ ), dissolved total nitrogen (DTN) and phosphorus (DTP), and total nitrogen (TN) and phosphorus (TP). Monthly DIN, TN, DIP, TP, water temperature, $\mathrm{pH}$, dissolved oxygen (DO) and transparency were also used for statistical analyses (described later). The chemical analyses and in-situ measurements were performed following the procedures described by the NIES (2013).

NIES counted the phytoplankton numbers for diatoms, cyanobacteria, green algae and other categories at sites $\mathrm{A}$ and $\mathrm{C}$ using an inverted microscope, and quantified the values as the biovolume by multiplying the counted cell number by the mean cell volume. We estimated the concentrations of biogenic $\mathrm{Si}(\mathrm{BSi})$ by multiplying diatom abundances by the BSi content of freshwater diatom frustules of $0.11 \mathrm{~g} . \mathrm{cm}^{-3}$ determined by averaging the values found in Bailey-Watts (1976a) and Sicko-Goad et al. (1984). The sum of DSi and BSi is expressed as $(D+B) \mathrm{Si}$ in the present study.

\section{Data analysis}

Field data were used for the following analyses: a $t$-test to detect long-term trends (with significance level of 0.05 ,
0.01 and 0.001 ), a correlation analysis to compare diatom abundance with water quality, and a Fourier analysis to determine characteristics of a seasonal pattern of diatom blooms. Because diatom blooms often occurred in winter during the 2000s and because about $60 \%$ of the annual minimum diatom abundance was observed in July or August during the 1981-2010 study period and the annual statistics were calculated based on the 12-month period from August to July and used for a correlation analysis. To compare seasonal characteristics of diatom blooms between past and current, the data were divided into three equal time periods (i.e., 1981-1990, 1991-2000 and 2001-2010) and used (e.g., for a Fourier analysis). $T$-test and Fourier analysis were also applied to model predictions described below.

\section{Model descriptions}

The long-term variation of the DSi concentration and the diatom abundance were simultaneously simulated using the simple four-box model. Fukushima (1984) developed the appropriate decoupling box models because some of the area (such as Takahama-iri and Tsuchiura-iri) might be independent in the lake. In the present study, a four-box model was used which has few optimized boxes to avoid complicated calculations (Fig. 1). We assumed that each box has constant water qualities along the water depth direction because the lake is so shallow that the stratigraphy is easily broken by the wind. The changes in DSi concentration and diatom abundance were simulated using the following equations:

$$
\begin{aligned}
& \frac{\mathrm{d} C_{\mathrm{DSi}_{, j}}}{\mathrm{~d} t}=\frac{I_{\mathrm{DSi}_{, j}}-O_{\mathrm{DSi}_{, j}}}{V_{j}}+\frac{R_{j}}{h_{j}}-b \mu_{j} C_{\mathrm{diatoms}, j_{j}}
\end{aligned}
$$

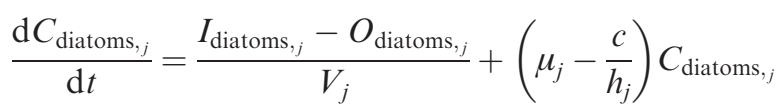

where $C$ is the concentration in the water column (DSi amount in $\mathrm{g} . \mathrm{m}^{-3}$; diatom cell volume in $\left.\mathrm{cm}^{3} \cdot \mathrm{m}^{-3}\right), t$ is the time (hour), $I$ and $O$ are the inflow and outflow, respectively (DSi in $\mathrm{g} . \mathrm{h}^{-1}$; diatoms in $\mathrm{cm}^{3} \cdot \mathrm{h}^{-1}$ ), $V$ is the lake volume $\left(\mathrm{m}^{3}\right.$, shown in Fig. 1$), R$ is the DSi release rate $\left(\mathrm{g} \cdot \mathrm{m}^{-2} \cdot \mathrm{h}^{-1}\right), h$ is the water depth ( $\mathrm{m}$, shown in Fig. 1$), b$ is the BSi content of freshwater diatom frustules $\left(\mathrm{g} . \mathrm{cm}^{-3}\right.$, calibrated), $\mu$ is the growth rate of freshwater diatoms $\left(\mathrm{h}^{-1}\right)$, and $c$ is the diatom sinking rate $\left(\mathrm{m} . \mathrm{h}^{-1}\right.$, calibrated). The subscript $j$ indicates the box number. The time step was $1 \mathrm{~h}$, which could provide enough time resolution for a decadal simulation.

\section{Inflow and outflow}

The inflow load $I$ consists of the loads produced by the inflowing rivers, extrusion flows from the upper boxes, and exchange flows from adjacent boxes. Details of the estimation are described in Supplements for model descriptions (online material available at: www.limnologyjournal.org). The outflow load $O$ was calculated by 
multiplying the concentration in the water column $C$ by the flow rate, on the assumption of the steady state of water level on each box.

\section{DSi release}

The DSi release rates $R$ could be described as the following equation:

$$
R_{j}=R_{\mathrm{SS}, j} S S_{\text {sed }, j_{j}} h_{j}+R_{\text {bottom }, j}
$$

where $R_{\mathrm{SS}}$ is the DSi release rate from resuspended sediments $\left(\mathrm{g} \cdot \mathrm{g}^{-1} \cdot \mathrm{h}^{-1}\right), S S_{\text {sed }}$ is the concentration of resuspended sediments attributing to the DSi release $\left(\mathrm{g} \cdot \mathrm{m}^{-3}\right)$, and $R_{\text {bottom }}$ is the DSi release rate from bottom sediments (g m$\left.{ }^{-2} \cdot \mathrm{h}^{-1}\right)$. The equations of $R_{\mathrm{SS}}$ and $R_{\text {bottom }}$ were determined by laboratory experiments (Arai et al., 2012), which are shown in Supplements for model descriptions of the online material.

The method for estimating $S S_{\text {sed }}$ differed between before 1997 and since 1998. Before 1997, the inorganic SS concentration was lower and did not change significantly (Arai et al., 2012). Therefore, the concentrations of resuspended sediments in 1997 were simulated by a sediment resuspension model developed by Seki et al. (2006), and they were applied to $S S_{\text {sed }}$ before 1997. After 1998, $S S_{\text {sed }}$ was estimated using the automatically monitored hourly turbidity (as a substitute for SS) and the chlorophyll $a$ concentrations at the four sites. Details of $S S_{\text {sed }}$ are shown in Supplements for model descriptions of the online material.

\section{Diatom growth}

Assuming that the possible limiting factors of the growth of diatoms are the light condition, the water temperature, and the DSi concentration in the lake, we calculated the growth rate of diatoms by the following equation:

$$
\mu_{j}=\mu_{\max } f_{\mathrm{I}_{, j}} f_{\mathrm{T}_{, j}} f_{\mathrm{Si}_{, j}}
$$

where $\mu_{\max }$ is the maximum growth rate of freshwater diatoms $\left(\mathrm{h}^{-1}\right.$, calibrated $)$ and $f_{\mathrm{I}}, f_{\mathrm{T}}$ and $f_{\mathrm{Si}}$ are the functions representing the influence of irradiance, temperature and DSi concentration on the growth of diatoms, respectively. In this model, $f_{\mathrm{I}}$ at a certain depth is obtained by the following equation:

$$
f_{\mathrm{I}_{, j}}=\frac{I R R_{j}}{K_{\mathrm{I}}+I R R_{j}}
$$

where $I R R$ is the irradiance in water at a certain depth $\left(\mathrm{MJ} . \mathrm{m}^{-2} \cdot \mathrm{h}^{-1}\right)$ and $K_{\mathrm{I}}$ is the half-saturation constant of irradiance (MJ.m ${ }^{-2} \cdot \mathrm{h}^{-1}$, calibrated). IRR was subject to Lambert-Beer's law as the following equation:

$$
I R R=I R R_{0} \exp \left(-K_{\mathrm{d}} z\right)
$$

where $I R R_{0}$ is the solar irradiance at the water surface, $K_{\mathrm{d}}$ is the vertically averaged light attenuation coefficient $\left(\mathrm{m}^{-1}\right)$, and $z$ is the water depth (m). Using equations (9) and (10), the vertically averaged light influence function $f_{\mathrm{I}}^{\prime}$; can be expressed by:

$$
f_{\mathrm{I}_{, j}}^{\prime}=\frac{1}{h_{j}} \int_{h_{j}}^{0} f_{\mathrm{I}_{, j}} \mathrm{~d} z=\frac{1}{K_{\mathrm{d}_{j}} \cdot h_{j}} \ln \left[\frac{I R R_{0}+K_{\mathrm{I}}}{I R R_{0} \exp \left(-K_{\mathrm{d}_{j}} \cdot h_{j}\right)+K_{\mathrm{I}}}\right] .
$$

The hourly $K_{\mathrm{d}}$ was estimated at each site by the regression formula based on the observed $K_{\mathrm{d}}$ and estimated $S S_{\text {sed }}$ as the follow:

$$
K_{\mathrm{d}, j}=\alpha_{0, j}+\alpha_{1, j} S S_{\text {sed }_{, j}}
$$

where $\alpha_{0}$ and $\alpha_{1}$ are the constant. Details of $I R R_{0}$ and $K_{\mathrm{d}}$ are shown in Supplements for model descriptions.

The temperature influence function $f_{\mathrm{T}}$ was obtained using the following formula by reference to Matsuoka (1984):

$f_{\mathrm{T}, j}= \begin{cases}\left(W T_{j}-d_{\mathrm{WT}}\right) / 14 & \left(W T_{j}<14+d_{\mathrm{WT}}\right) \\ 1 & \left(14+d_{\mathrm{WT}} \leq W T_{j}<20+d_{\mathrm{WT}}\right) \\ 2-\left(W T_{j}-d_{\mathrm{WT}}\right) / 20 & \left(20+d_{\mathrm{WT}} \leq W T_{j}\right)\end{cases}$

where $W T$ is the water temperature $\left({ }^{\circ} \mathrm{C}\right)$ and $d_{\mathrm{WT}}$ is the constant $\left({ }^{\circ} \mathrm{C}\right.$, calibrated). $W T$ was determined by interpolating the monthly data taken by NIES.

The influence function of the DSi concentration $f_{\mathrm{Si}}$ was obtained using the Monod equation as follows:

$$
f_{\mathrm{Si}_{, j}}=\frac{C_{\mathrm{DSi}_{, j}}}{K_{\mathrm{Si}}+C_{\mathrm{DSi}_{, j}}}
$$

where $K_{\mathrm{Si}}$ is the half-saturation constant of the DSi concentration for diatoms $\left(\mathrm{g} \mathrm{m}^{-3}\right.$, calibrated). For simplicity, the present model assumed that an influence of $\mathrm{N}$ and $\mathrm{P}$ on diatom blooms could be negligible. The nutrient limitations for diatoms were discussed using the field data in the Discussion section.

\section{Parameter calibration}

We calibrated the parameters $b, \mu_{\max }, K_{\mathrm{I}}, d_{\mathrm{WT}}, K_{\mathrm{Si}}$ and $c$ for every fifth year $(1981,1986,1991,1996,2001$ and 2006). The parameter sets were determined by random sampling and the least-squares method. For the random sampling, we assigned the ranges of $b, \mu_{\max }$, and $c$ based on the literature values (Table 1), while the sufficient ranges of $K_{\mathrm{I}}, d_{\mathrm{WT}}$ and $K_{\mathrm{Si}}$ were assigned after a sensitive analysis. More information of the calibration methods are shown in Supplements for model descriptions. Finally, the calibrated parameters are shown in Table 1. After the parameter identification, the parameter sets were not changed during the model validation for the entire period.

\section{Examination of factors influencing diatom blooms using the model}

The concentration of $S S_{\text {sed }}$ increased remarkably (280\% increase from 1981-1990 to 2001-2010; Fig. S1 of 
Table 1. Values of the diatom parameters determined in the previous studies and calibrated in this study.

\begin{tabular}{lrr}
\hline Parameters & Literature values & Calibrated values \\
\hline BSi content of diatom frustules, $b\left(\mathrm{~g} \cdot \mathrm{cm}^{-3}\right)$ & $0.07-0.13^{\mathrm{a}}$ & 0.067 \\
Maximum growth rate of diatoms, $\mu\left(\mathrm{h}^{-1}\right)$ & $0.07-0.10^{\mathrm{b}}$ & 0.092 \\
Half-saturation constant of irradiance, $K_{\mathrm{I}}\left(\mathrm{MJ} \cdot \mathrm{m}^{-2} \cdot \mathrm{h}^{-1}\right)$ & & 0.028 \\
Water temperature constant, $d_{\mathrm{WT}}\left({ }^{\circ} \mathrm{C}\right)$ & & -4.7 \\
Half-saturation constant of $\mathrm{DSi}, K_{\mathrm{Si}}\left(\mathrm{g} \cdot \mathrm{m}^{-3}\right)$ & $0.8-2.8^{\mathrm{c}}$ & 3.1 \\
Sinking rate of diatoms, $c\left(\times 10^{-2} \mathrm{~m} \cdot \mathrm{h}^{-1}\right)$ & 1.8 \\
\hline
\end{tabular}

${ }^{a}$ Bailey-Watts (1976a), Sicko-Goad et al. (1984), Conley et al. (1989) and Takano and Hino (1996).

b Matsuoka (1984).

${ }^{c}$ Bailey-Watts (1976b), Gibson (1984) and Ferris and Lehman (2007).

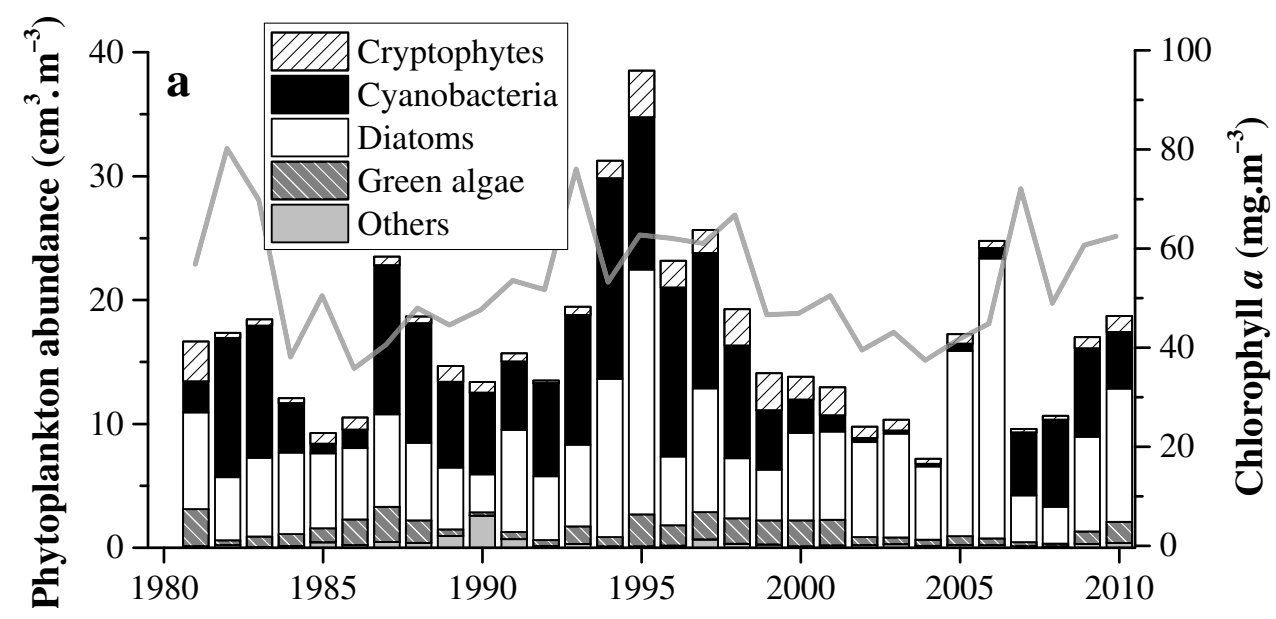

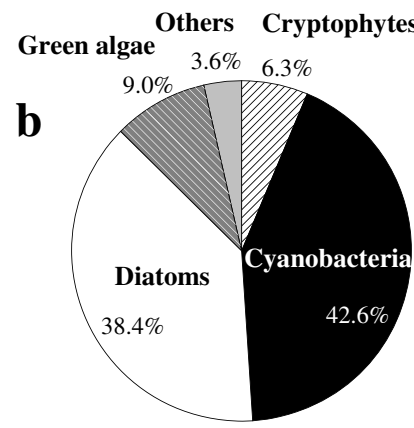

1981-1990

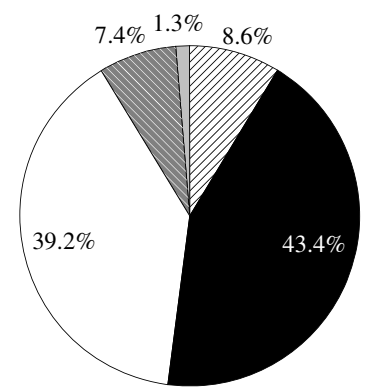

1991-2000

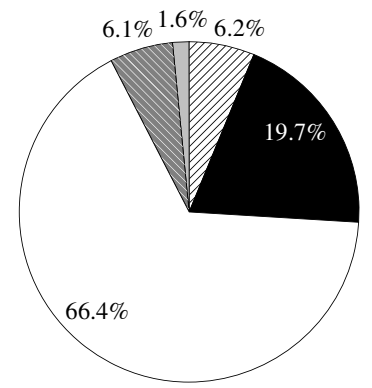

2001-2010

Fig. 2. Long-term change in phytoplankton abundances and chlorophyll $a$ concentrations (a) and mean proportion of cell volumes of the respective phytoplankton groups during 1981-1990, 1991-2000 and 2001-2010 (b) at site C in Lake Kasumigaura.

the online material), which caused both an increase in the DSi release amount and a degradation of the light conditions (equations 3 and 8). For an assessment of those impacts on the long-term changes in diatom blooms, we compared the predictions between the following three scenarios: (1) the conditions described in "Model description" above (expressed as the standard simulation in the present study), (2) no recent intense resuspension (i.e., applying the annual variation of the concentration of resuspended sediments simulated in 1997 to $S S_{\text {sed }}$ in equations (3) and (8) in every year; expressed as Case 1), and (3) the recent sediment resuspension occurred (and a light condition degraded) but the DSi release rate from SS was zero during the entire period (i.e., $R_{\mathrm{SS}}=0$ in equation (3); expressed as Case 2).

\section{Results}

\section{Field observations}

\section{Dominant phytoplankton species in Lake Kasumigaura}

In Lake Kasumigaura, diatoms and cyanobacteria occupied about $80 \%$ of all phytoplankton cell volume on average during the 1981-2010 study period. Although significant trends of chlorophyll $a$ concentration and total phytoplankton abundance were not detected (Fig. 2(a)), the dominant species changed remarkably from cyanobacteria to diatoms (Fig. 2(b)).

Actinocyclus spp., Aulacoseira spp., Cyclotella spp., Fragilaria spp. and Synedra spp., occupied about $90 \%$ of 

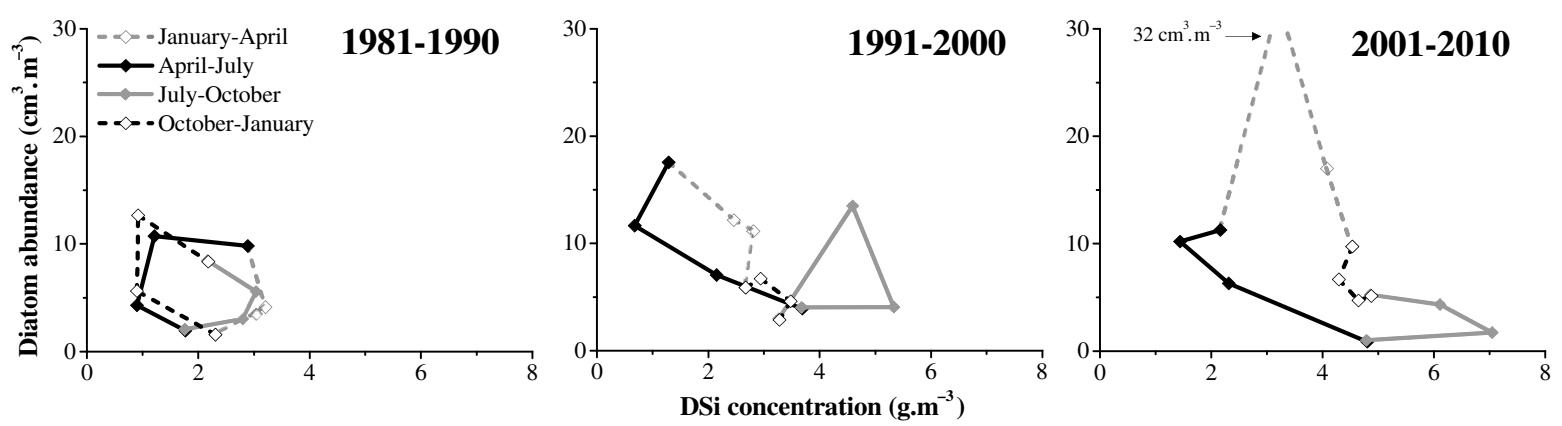

Fig. 3. Seasonal changes of DSi concentration and diatom abundance at site C averaged during 1981-1990, 1991-2000 and 2001-2010.

all diatom cell volume on average. Actinocyclus spp., blooming often in autumn, disappeared after 1992 and Cyclotella spp. were strongly dominant during the 2000s. Massive blooming was seen during 1994-1995 and 20052006 (Fig. 2(a)), consisting mainly of Synedra spp. and Cyclotella spp., respectively.

\section{Long-term trend of diatom abundance and water quality and their relationships}

We detected a trend of increasing diatom abundance at site C during 1981-2010 (12-month moving average, $P<0.001)$. The mean abundance of diatoms for 1981-1990, 1991-2000 and 2001-2010 was 6.0, 8.4 and $9.2 \mathrm{~cm}^{3} . \mathrm{m}^{-3}$, respectively. As for nutrients, the concentrations of DSi, $(D+B) \mathrm{Si}$, DIP and TP significantly increased, while DIN and TN were significantly decreased $(P<0.001)$. In addition, significant trends of the increasing water temperature and decreasing $\mathrm{pH}$ and transparency were detected $(P<0.001)$.

The annual maximum diatom abundance was significantly related to the annual maximum DSi concentration $\left(r^{2}=0.16, P<0.05\right)$ and the $(D+B)$ Si concentration $\left(r^{2}=0.59, P<0.001\right.$; Fig. S2 of the online material). However, the annual maximum diatom abundance was not significantly related to the annual maximum values of other nutrients such as DIP, TP, DIN and TN $\left(r^{2}<0.07\right)$ and the annual mean values of potential factors influencing diatom blooms such as water temperature, $\mathrm{pH}, \mathrm{DO}$ $\left(r^{2}<0.01\right)$ and transparency $\left(r^{2}=0.07\right)$.

\section{Shift of blooming season}

We investigated seasonal relationships between DSi concentration and diatom abundance in light of the role of DSi as a factor limiting diatom growth. Many relationships between the DSi concentration and diatom abundance over the last three decades showed a counterclockwise loop. This characteristic could be clearly confirmed by averaging the relationships for each decade (Fig. 3). These hysteresis loops represent the following: (i) diatom growth by the uptake of DSi under preferable conditions (e.g., at optimal temperature), (ii) the rapid sinking of diatoms after DSi depletion, and (iii) almost no diatoms with the DSi supply by inflowing DSi-rich river water and release from sediments.
The relationships were mostly characterized as a tworound loop during the 1980s with spring and autumn diatom blooms (e.g., 1983, 1986 and 1987), with a large one-round loop during the 2000s with extensive winterspring blooms (e.g., 2002, 2003 and 2005). It means a shift of blooming season during the study period. In fact, seasonal $t$-tests showed that the diatom abundance increased significantly in January $(P<0.01)$, February, and March $(P<0.05)$ and decreased significantly in November $(P<0.01)$ during the study period. Moreover, the power spectrum obtained by the Fourier analysis showed that diatom blooms had a cyclic period of 6 and 12 months, which changed from twice a year for 1981-1990 to once a year for 2001-2010 (Fig. S3 of the online material).

\section{Simulation}

\section{Long-term trend and seasonality of model predictions}

The model predictions for the DSi and the diatoms in BOX 3, including the center of the lake, are shown in Figure 4. The validation results showed that the rootmean-squared error (RMSE) was 2.6 g.m ${ }^{-3}$ for the DSi and $13 \mathrm{~cm}^{3} \cdot \mathrm{m}^{-3}$ for the diatoms.

Although the peaks of massive diatom blooms were underestimated in some years (e.g., 1994, 2005 and 2006), long-term trends of increasing DSi and increasing diatoms were detected in the model predictions as well as the observed data $(12$-month moving average; $P<0.001)$. In addition, the Fourier analysis of model predictions showed the changes of blooming frequency from twice a year for 1981-1990 to once a year for 2001-2010 (Fig. S3). In fact, the observed shift of seasonal relationships between DSi and diatoms, from a two-round loop to a large one-round loop, was nearly simulated (Fig. 5(a)).

\section{Effects of the DSi release and the degradation of light conditions caused by sediment resuspension on the long-term changes in diatom blooms}

We found that the calculated DSi concentrations and diatom abundances under no recent intense resuspension (Table 2, Case 1) were usually lower than those obtained by the standard simulation during the 2000s (Fig. S4 of the online material). In fact, there was no significant trend for 

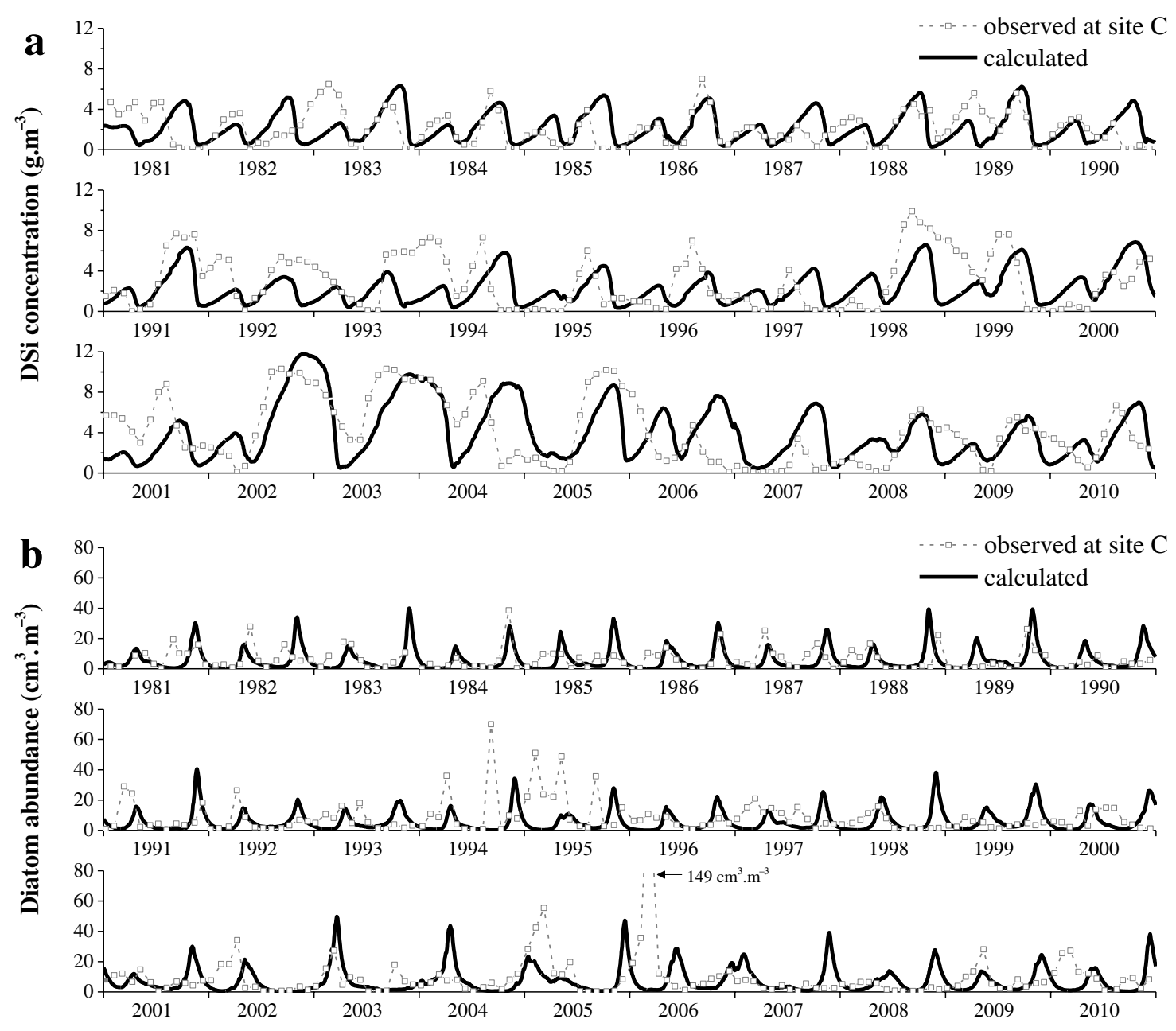

Fig. 4. Model predictions in BOX 3 (the standard simulation; solid lines) and observed data at site C (broken lines and points) for DSi (a) and diatoms (b) in Lake Kasumigaura during 1981-2010.

the results of Case 1. Seasonal relationships between the DSi and diatoms of Case 1 showed a two-round loop on an average for 2001-2010 (Fig. 5(b)), unlike the results obtained with the standard simulation (Fig. 5(a)). On the other hand, the results of Case 2, assuming that the DSi release rate from resuspended sediments was zero, represented diatom blooms at once a year during some years (e.g., 2003 and 2004) (Table 2; Figs. 5(c) and S4). Therefore, the DSi release from resuspended sediments alone could never explain the observed change in the seasonality of diatom blooms. These results suggested that the degradation of the light conditions by resuspension might play an important role in the shift of blooming season.

In Case 2, the annual maximum diatom abundance in BOX 3 was $20-50 \%$ lower than those obtained by the standard simulation method for 2002-2006 (Fig. S4), which is nearly the same as in Case 1, indicating the impacts of the recent release on diatom blooms in the lake. Although the annual maximum DSi concentrations of Case 2 were about $20-30 \%$ lower than those obtained by the standard simulation for the same period, an increasing trend of DSi concentration was detected $(P<0.001)$, suggesting the impacts of a weakening of diatom blooms due to the effect of the degradation of light conditions on the DSi concentration.

We thus propose the following scenario concerning the winter-spring blooms observed in recent years in Lake Kasumigaura: (1) the beginning of autumn blooms was delayed due to the degradation of light conditions and (2) the blooms lasted until spring due to the high DSi concentration derived from the release of DSi from resuspended sediments. Diatom blooms were observed during the winter-spring period but not in summer-autumn, which might be related to strong limitations imposed by temperature conditions in the summer remaining longer than those in winter.

\section{Discussion}

\section{Nutrient limitation for diatoms}

Marine diatoms typically take up N, P and $\mathrm{Si}$ at the atomic ratio of 1 for $\mathrm{Si} / \mathrm{N}$ and 16 for $\mathrm{Si} / \mathrm{P}$, which is well known as the Redfield ratio (Redfield et al., 1963; 

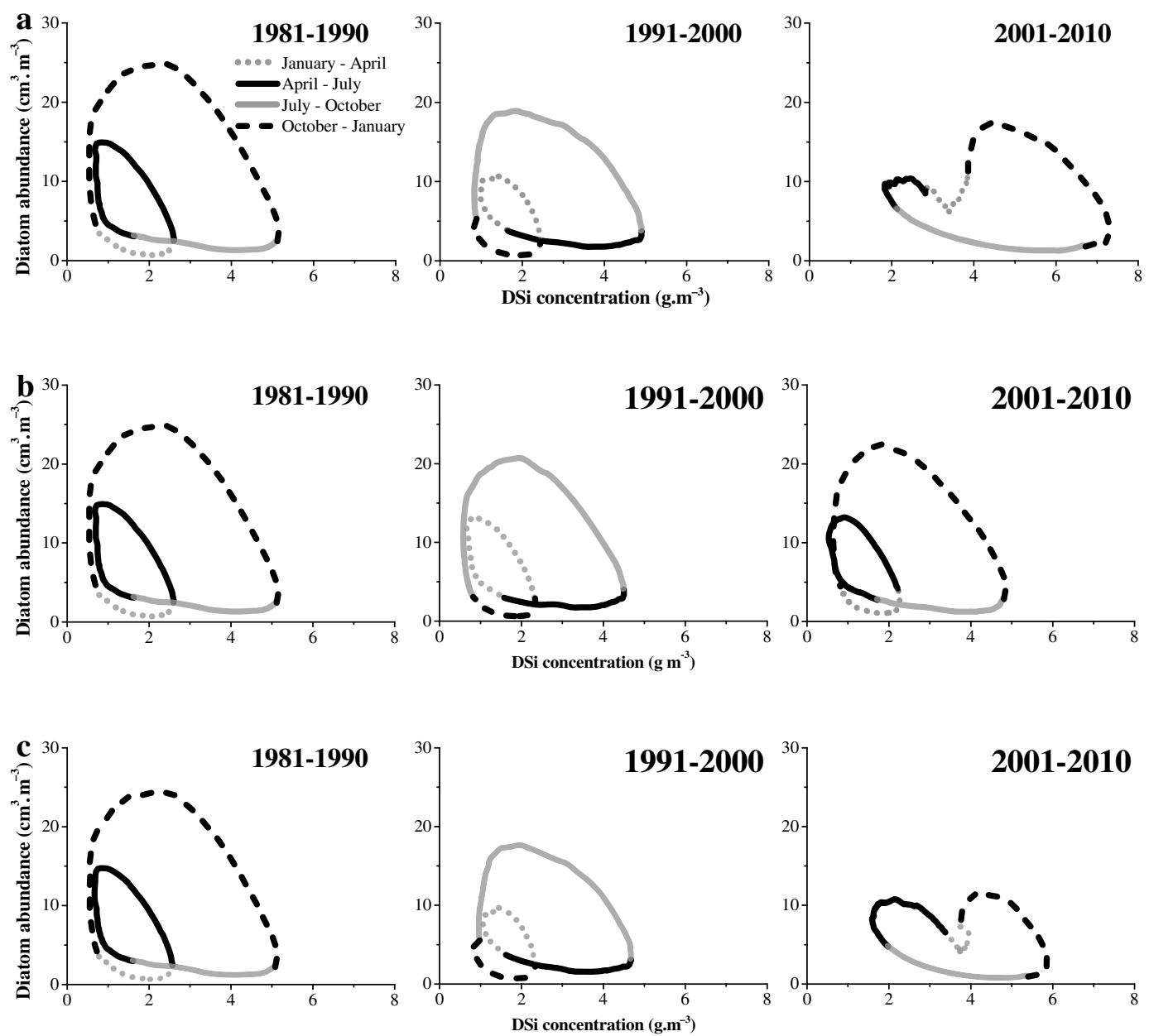

Fig. 5. Seasonal changes of DSi concentration and diatom abundance in BOX 3 calculated by the standard simulation (a) and the simulation of Case 1 (b) and of Case 2 (c) averaged during 1981-1990, 1991-2000 and 2001-2010.

Table 2. Input variables and model parameters (a) and the simulated trends from the 1981-1990 period to the 2001-2010 period (b) of the standard simulation and of the simulation of Cases 1 and 2.

\begin{tabular}{|c|c|c|c|}
\hline Input variables or parameters & Standard simulation & Case 1 & Case 2 \\
\hline (a) Input variables and parameters & & & \\
\hline \multicolumn{4}{|l|}{ SS concentration derived from sediments, $S S_{\text {sed }}$} \\
\hline 1981-1997 & $*$ & $*$ & * \\
\hline 1998-2010 & $* *$ & $*$ & $* *$ \\
\hline DSi release rate from resuspended sediments, $R_{\mathrm{SS}}$ & Estimated $^{\mathrm{a}}$ & Estimated $^{\mathrm{a}}$ & Zero \\
\hline \multicolumn{4}{|l|}{ (b) Long-term trends } \\
\hline DSi amount released from $S S_{\text {sed }}{ }^{\text {b }}$ & $\uparrow$ & $\rightarrow$ & $\rightarrow$ \\
\hline Light attenuation coefficient, $K_{\mathrm{d}}{ }^{\mathrm{b}}$ & $\uparrow$ & $\rightarrow$ & $\uparrow$ \\
\hline Diatom abundance $^{b}$ & $\uparrow$ & $\rightarrow$ & $\downarrow$ \\
\hline \multicolumn{4}{|l|}{ Frequency of blooms per year } \\
\hline $1981-1990$ & 2 & 2 & 2 \\
\hline $2001-2010$ & 1 & 2 & $\sim 1$ \\
\hline
\end{tabular}

* Hourly-simulated in 1997 by a sediment resuspension model developed by Seki et al. (2006).

** Estimated using hourly-observed turbidity and chlorophyll $a$ in each year.

${ }^{a}$ Estimated by the equations developed by Arai et al. (2012).

$\mathrm{b} \uparrow$, increase; $\downarrow$, decrease; $\rightarrow$, no significant trend.

Brzezinski, 1985). In contrast, freshwater diatoms usually need more Si than marine diatoms. Nagai et al. (2001) reported that the $\mathrm{Si} / \mathrm{N}$ and $\mathrm{Si} / \mathrm{P}$ atomic ratios of diatoms collected in Lake Biwa in Japan were 3-14 times higher than the Redfield ratio. These ratios could be used for analyzing the limiting nutrients for diatoms. Therefore, the nutrient atomic ratios were investigated in Lake Kasumigaura during the 1981-2010 study period. We 
Table 3. $(\mathrm{D}+\mathrm{B})$ Si budgets in Lake Kasumigaura estimated by budgetary analysis in Arai and Fukushima (2012) and calculated by the standard simulation in the present study.

\begin{tabular}{|c|c|c|c|c|c|c|}
\hline \multirow[b]{2}{*}{$\left(10^{9}\right.$ g.year $\left.{ }^{-1}\right)$} & \multicolumn{3}{|c|}{ Budgetary analysis } & \multicolumn{3}{|c|}{ The standard simulation } \\
\hline & $\overline{1980-2007}$ & $1980 \mathrm{~s}$ & $2000-2007$ & $\overline{1981-2010}$ & $1981-1990$ & $2001-2010$ \\
\hline River input of DSi & $8-12$ & $8-12$ & $8-12$ & 8 & 8 & 7 \\
\hline BSi gross sedimentation & $8-30$ & $5-16$ & $13-46$ & 10 & 10 & 10 \\
\hline Apparent accumulation $^{\mathrm{a}}$ & 10 & 10 & 10 & & & \\
\hline DSi release & & & $5-7$ & 5 & 5 & 7 \\
\hline
\end{tabular}

${ }^{a}$ Determined by sediment core analysis in Arai and Fukushima (2012).

compared $(D+B) \mathrm{Si}$ with $\mathrm{TP}$ and $\mathrm{TN}$ since lithogenic $\mathrm{Si}$ was not considered a nutrient for diatoms.

We found that the $100 \%$ of $(D+B) \mathrm{Si} / \mathrm{TN}, \mathrm{DSi} / \mathrm{DTN}$, and $(D+B) \mathrm{Si} / \mathrm{TP}, 70 \%$ of $\mathrm{DSi} / \mathrm{DTP}$, and $62 \%$ of $\mathrm{DSi} / \mathrm{DIN}$ atomic ratios were equal to or less than the corresponding ratios of freshwater diatoms when the annual maximum diatom abundance was observed (Fig. S5 of the online material). In contrast, $70 \%$ of DSi/DIP atomic ratios were higher than the $\mathrm{Si} / \mathrm{P}$ ratio of freshwater diatoms. However, Ptacnik et al. (2010) concluded the ratio of DIN to TP as the best performing indicator for phytoplankton $\mathrm{N}$ versus $\mathrm{P}$ limitation considering the availability, suggesting that the DSi/DIN ratio is the adequate indicator for inferring nutrient limitations, but not the DSi/DIP ratio. These findings suggest that DSi might be one of the main factors limiting the growth of diatoms in the lake during a bloom season.

\section{Comparison of budgetary calculations}

We compared $(D+B)$ Si budgets determined by our model simulation with those obtained by budgetary analysis based on a water quality database and chronological sediment information, reported by Arai and Fukushima (2012) (Table 3). The values of model predictions were close to those described by Arai and Fukushima (2012) on average during the last three decades. Based on the simulation, about $50 \%$ of the DSi transported through the inflows was taken by diatoms and ultimately accumulated in the bottom sediments over 30 years, which are close to the percentages $60-70 \%$ obtained by Arai and Fukushima (2012).

Although the recent amount of DSi released from SS calculated by our model simulation was close to the maximum estimation obtained by the budgetary analysis during the 2000s, the increase in the river output of $(D+B)$ Si was not as high as that in the results of the budgetary analysis. This might be caused by the DSi uptake by diatoms and their rapid sinking in the model. The BSi gross sedimentation shown by the simulation was equal to or lower than that shown by budgetary analysis, but it was close to the BSi apparent accumulation rate calculated by analyzing sediment cores. This suggests the underestimation of the gross sedimentation due to inaccuracy in the peaks of diatom blooms in our model and/or the overestimation of the gross sedimentation by the budgetary analysis by Arai and Fukushima (2012), due to incompatibility of the parameters such as the diatom-sinking rate.

\section{Similarity/dissimilarity between predictions and observations}

We compared the annual statistics for model predictions in BOX 3 with field observations at site $\mathrm{C}$. The coefficients of variance $(\mathrm{CV})$ of RMSE for the annual means, standard deviations and maximum DSi concentrations were less than $50 \%$. The model predictions were significantly related to the observed data for the annual means and maximum DSi concentrations $(P<0.001)$, but not for the annual standard deviation and minimum values $(P=0.07-0.11)$. In contrast, the CV of RMSE for the annual standard deviations, maximum and minimum diatom abundances was more than $80 \%$, whereas the CV for the annual mean diatom abundance was $59 \%$. The model predictions were not significantly related to the observation data $(P=0.09-0.46)$ except for the annual standard deviation $(P<0.05)$.

\section{Causes for the dissimilarity}

The validation results showed that the long-term changes in diatom abundances were simulated with less sufficient accuracy than those of the DSi concentrations. In fact, most of the high peaks of diatom blooms were underestimated by the model simulation (e.g., in 1994, 1995, 2005 and 2006; Fig. 4). Such errors might be improved in part by considering the changes in diatom parameters (such as BSi content, growth rate and sinking rate) due to a shift of dominant species and growing stages, an insufficiency of the parameter calibration due to scanty observation data, and an influence of other nutrients such as $\mathrm{N}$ and $\mathrm{P}$.

Diatom abundance was underestimated during 1994 and 1995 (Fig. 4), when significant blooms consisting of Synedra spp. were transiently observed. It might mainly be caused by the shift of dominant species. 
Shatwell et al. (2013), using continuous and batch culture experiments, found that the types of interaction between silicate, temperature and photoperiod differed among species.

Several studies have indicated that the diatom-sinking rate was different between the growing season and the depletion season; that is, the rapid sinking of diatoms occurs under nutrient limitations in fresh water (Titman and Kilham, 1976; Sommer and Stabel, 1983; Conley et al., 1989) and in physically stable water columns (Reynolds, 1973; Scavia and Fahnenstiel, 1987). In the present study, the peaks of diatom abundance were lower than the observed peaks in the first half of 2005 and 2006 even though the beginning of the blooms was relatively well simulated (Fig. 4), which might be caused by an overestimation of the diatom-sinking rate before nutrient limitations. It might be the cause of an underestimation of the river output of $(D+B)$ Si during the 2000s (Table 3).

The error might be attributable in part to the time intervals of the observation data used in the calibration. We used monthly observation data for the parameter calibration, but the enormous variation of diatom abundance was observed at site $\mathrm{C}$ by NIES within some 1-month periods (e.g., $5.0 \mathrm{~cm}^{3} \cdot \mathrm{m}^{-3}$ on 20th September 1984, $24 \mathrm{~cm}^{3} \cdot \mathrm{m}^{-3}$ on 4 th October 1984 and $5.5 \mathrm{~cm}^{3} \cdot \mathrm{m}^{-3}$ on 24th October 1984).

Modeling the influence of $\mathrm{N}$ and $\mathrm{P}$ dynamics on diatom blooms might also improve the model accuracy. $\mathrm{N}$ or $\mathrm{P}$ could limit the growth of diatoms when DSi concentration remains in a high level, while Si could be regarded as the main limitation factor when dominant bloom occurred and DSi concentration depleted.

\section{Other factors influencing the long-term changes in diatom blooms}

Although the significant relationship of between annual minimum water temperature and annual maximum diatom abundance was not detected, the significant increase in water temperature might possibly cause an increase in the winter diatom blooms. The temperature data used in this study were obtained monthly, causing the error derived from daily and day-by-day fluctuations. Therefore, more frequent data (e.g., hourly values) of water temperature should be analyzed, especially in winter.

Regarding nutrients for diatoms, the increase in the $\mathrm{P}$ concentration observed in the lake during the last three decades might also be related to diatom blooms. However, the correlation analysis and the nutrient atomic ratios obtained in the present study indicated that the $\mathrm{Si}$ was more adequate factor limiting diatom growth when blooming.

Although we considered only the physical environment in our estimates of diatom abundances in the model, diatom abundance was probably influenced by physiological and/or ecological factors such as the appearance of other phytoplankton and predation pressure. In fact, several drastic changes in dominant phytoplankton groups were observed in the lake during the last few decades and a number of factors were discussed (Takamura et al., 1992; Imai et al., 1999; Tomioka et al., 2011), which might be related to the long-term trend of diatom abundance. However, the typical seasonality was closely simulated in past and current by our box model considering only the physical environment. This result suggests that the physical environment is one of the causes of the observed changes.

In Lake Kasumigaura, a shift of dominant diatom species was observed over 30 years. During the 2000s, Cyclotella spp., especially C. meneghiniana, were most dominant. Their growth rate is relatively fast (Matsuoka, 1984), and thus they could form extended blooms under better conditions for them such as high DSi concentrations. This might also be related to the underestimation of peaks of recent diatom abundance based on the model simulation with the constant diatom parameters (Fig. 4).

\section{Conclusions}

In Lake Kasumigaura, diatom abundance significantly increased and the seasonality of diatom blooms shifted from spring and autumn to the winter-spring period over the past three decades. Our modeling and simulation of major processes involved in DSi and diatoms showed the similar trend to the observations, even though the peaks of the blooms were underestimated in some years. The model simulations indicated the significant impacts of the recent DSi release from resuspended sediments on the long-term increase in diatom abundance in the lake. In addition, the shift of the dominant season of diatoms could be explained by the degradation of light conditions by the resuspension of bottom sediments. These findings implicate the significance of the effects of the interactions between sediments and water on phytoplankton blooms. The results also suggested that Si monitoring is useful for the management and prediction of diatom blooms in eutrophic lakes.

The present study focused on the relationships between Si dynamics and the development of diatoms; however, other nutrients such as $\mathrm{N}$ and $\mathrm{P}$ should be included in the model for confirming the importance of $\mathrm{Si}$ as a nutrient for diatoms. In addition, the effects of Si dynamics on a shift of dominant phytoplankton species remain poorly understood because of their complexity related to biogeochemistry and physiology. In Lake Kasumigaura, the cyanobacteria abundance declined when diatoms were dominant during the 2000s, indicating the possibility of preventing harmful algae by regulating diatom blooms. For this reason, continuous monitoring may be of even more significance. For Lake Kasumigaura, detailed studies to identify the mechanisms underlying the intense sediment resuspension in the lake during the early 2000 s are also needed.

Online Supplemental Material is available at: www.limnology-journal.org 
Acknowledgements. The authors wish to thank the National Institute for Environmental Studies for providing valuable data. This report was supported in part by a grant-in-aid for a Research Fellowship of the Japan Society for the Promotion of Science (JSPS) No. 23.372 awarded to H. Arai from the Ministry of Education, Culture, Sports, Science and Technology, Japan.

\section{References}

Arai H. and Fukushima T., 2012. Silicon budget of eutrophic Lake Kasumigaura, Japan. J. Soils Sediments, 12, 1501-1507.

Arai H., Fukushima T. and Komatsu K., 2012. Increase in silicon concentrations and release from suspended solids and bottom sediments in Lake Kasumigaura, Japan. Limnology, $13,81-95$.

Bailey-Watts A.E., 1976a. Planktonic diatoms and some diatomsilica relations in a shallow eutrophic Scottish loch. Freshw. Biol., 6, 69-80.

Bailey-Watts A.E., 1976b. Planktonic diatoms and silica in Loch Leven, Kinross, Scotland: a one month silica budget. Freshw. Biol., 6, 203-213.

Barbiero R.P., Tuchman M.L., Warren G.J., and Rockwell D.C., 2002. Evidence of recovery from phosphorus enrichment in Lake Michigan. Can. J. Fish. Aquat. Sci., 59, 16391647.

Bormans M. and Webster I.T., 1999. Modelling the spatial and temporal variability of diatoms in the River Murray. J. Plankton Res., 21, 581-598.

Brzezinski M.A., 1985. The Si:C:N ratio of marine diatoms: interspecific variability and the effect of some environmental variables. J. Phycol., 21, 347-357.

Callies U., Scharfe M. and Ratto M., 2008. Calibration and uncertainty analysis of a simple model of silica-limited diatom growth in the Elbe River. Ecol. Modell., 213, 229-244.

Conley D.J., Kilham S.S. and Theriot E., 1989. Differences in silica content between marine and freshwater diatoms. Limnol. Oceanogr., 34, 205-213.

Conley D.J., Sommer M., Meunier J.D., Kaczorek D. and Saccone L., 2006. Silicon in the terrestrial biogeosphere. In: Ittekkot V., Unger D., Humborg C. and Tac An N. (eds.), The Silicon Cycle: Human Perturbations and Impacts on Aquatic Systems, Island, Washington, DC, 13-28.

Ferris J.A. and Lehman J.T., 2007. Interannual variation in diatom bloom dynamics: roles of hydrology, nutrient limitation, sinking, and whole lake manipulation. Water Res., 41, $2551-2562$.

Foundation of River and Watershed Environment Management, 2007. Research of the runoff mechanism for silicate and other dissolved inorganic matters in river (in Japanese).

Fukushima T., 1984. Studies on the change characteristics and management of water quality in a shallow lake (in Japanese).

Fukushima T., Kawamura S., Seki T., Onda Y., Imai A. and Matsushige K., 2005. Why has Lake Kasumigaura become turbid? Verh. Int. Verein. Limnol., 29, 732-737.

Fukushima T., Kamiya K., Onda Y., Imai A. and Matsushige K., 2010. Long-term changes in lake sediments and their influences on lake water quality in Japanese shallow lakes. Fund. App. Limnol., 177, 177-188.
Gibson C.E., 1984. Sinking rates of planktonic diatoms in an unstratified lake: a comparison of field and laboratory observations. Freshw. Biol., 14, 631-638.

Harashima A., Kimoto T., Wakabayashi T. and Toshiyasu T., 2006. Verification of the silica deficiency hypothesis based on biogeochemical trends in the aquatic continuum of Lake Biwa - Yodo River - Seto Inland Sea, Japan. AMBIO, 35, $36-42$.

Havens K.E., Fukushima T., Xie P., Iwakuma T., James R.T., Takamura N., Hanazato T. and Yamamoto T., 2001. Nutrient dynamics and the eutrophication of shallow lakes Kasumigaura (Japan), Donghu (PR China), and Okeechobee (USA). Environ. Pollut., 111, 263-272.

Humborg C., Ittekkot V., Cociasu A. and Bodungen B., 1997. Effect of Danube river dam on Black sea biogeochemistry and ecosystem structure. Nature, 386, 385-388.

Imai A., Fukushima T., and Matsushige K., 1999. Effects of iron limitation and aquatic humic substances on the growth of Microcystis aeruginosa. Can. J. Fish. Aquat. Sci., 56, 1929-1937.

Ittekkot V., Humborg C. and Schafer P., 2000. Hydrological alterations and marine biogeochemistry: a silicate issue? Bioscience, 50, 776-782.

Köhler J., Hilt S., Adrian R., Nicklisch A., Kozerski H.P. and Walz N., 2005. Long-term response of a shallow, moderately flushed lake to reduced external phosphorus and nitrogen loading. Freshw. Biol., 50, 1639-1650.

Koszelnik P. and Tomaszek J.A., 2008. Dissolved silica retention and its impact on eutrophication in a complex of mountain reservoirs. Water Air Soil Pollut., 189, 189-198.

Kristiansen S. and Hoell E.E., 2002. The importance of silicon for marine production. Hydrobiologia, 484, 21-31.

Li M., Xu K., Watanabe M. and Chen Z., 2007. Long-term variations in dissolved silicate, nitrogen, and phosphorus flux from the Yangtze River into the East China Sea and impacts on estuarine ecosystem. Estuar. Coast. Shelf. Sci., 71, $3-12$.

Matsuoka Y., 1984. An eutrophication model of Lake Kasumigaura. Res. Rep. Natl. Inst. Environ. Stud. Jpn., 54, 53-242 (in Japanese with English abstract).

Muraoka K. and Fukushima T., 1986. On the box model for prediction of water-quality in eutrophic lakes. Ecol. Modell., $31,221-236$.

Nagai M., Sugiyama M. and Hori T., 2001. Environmental chemistry of rivers and lakes, Part VII. Fractionation by calculation of suspended particulate matter in Lake Biwa into three types of particles of different origins. Limnology, 2, $147-155$.

NIES, 2013. Lake Kasumigaura Database. Available online at: http://db.cger.nies.go.jp/gem/moni-e/inter/GEMS/database/ kasumi/contents/database/datalist.html, Cited on 16 August 2013.

Officer C.B. and Ryther J.H., 1980. The possible importance of silicon in marine eutrophication. Mar. Ecol. Prog. Ser., 3, 83-91.

Ptacnik R., Andersen T., and Tamminen T., 2010. Performance of the Redfield Ratio and a family of nutrient limitation indicators as thresholds for phytoplankton N vs. P limitation. Ecosystems, 13, 1201-1214.

Redfield A.C., Ketchum B.H. and Richards F.A., 1963. The influence of organismson the composition of sea-water. In: Hill M.N. (ed.), The Sea, Volume 2: The Composition 
of Sea-Water Comparative and Descriptive Oceanography, Harvard University Press, Cambridge, 26-77.

Reynolds C.S., 1973. The seasonal periodicity of planktonic diatoms in a shallow eutrophic lake. Freshw. Biol., 3, 89-110.

Scavia D. and Fahnenstiel G.L., 1987. Dynamics of Lake Michigan phytoplankton: mechanisms controlling epilmnetic communities. J. Great Lakes Res., 13, 103-120.

Schelske C.L., 1985. Biogeochemical silica mass balances in Lake Michigan. Biogeochemistry, 1, 197-218.

Schelske C.L., 1999. Diatoms as mediators of biogeochemical silica depletion in the Laurentian Great Lakes. In: Stoermer E.F. and Smol J.P. (eds.), The Diatoms: Applications for the Environmental and Earth Science. Cambridge University, Cambridge, 73-84.

Seki T., Fukushima T., Imai A. and Matsushige K., 2006. Turbidity increase and sediment resuspension in Lake Kasumigaura. Doboku Gakkai Ronbunshu G, 62, 122-134 (in Japanese with English abstract).

Shatwell T., Köhler J. and Nicklisch A., 2013. Temperature and photoperiod interactions with silicon-limited growth and competition of two diatoms. J. Plankton Res., 35, 957-971.

Sicko-Goad L., Schelske C.L. and Stoermer E.F., 1984. Estimation of intracellular carbon and silica content of diatoms from natural assemblages using morphometric techniques. Limnol. Oceanogr., 29, 1170-1178.

Sommer U. and Stabel H.H., 1983. Silicon consumption and population density changes of dominant planktonic diatoms in Lake Constance. J. Ecol., 71, 119-130.

Takamura N., Otsuki A., Aizaki M. and Nojiri Y., 1992. Phytoplankton species shift accompanied by transition from nitrogen dependence to phosphorus dependence of primary production in Lake Kasumigaura, Japan. Arch. Hydrobiol., $124,129-148$.

Takano K. and Hino S., 1996. The effect of silicon concentration on replacement of dominant diatom species in a silicon-rich Lake. Jpn. J. Limnol., 57, 153-162.

Teodoru C., Dimopoulos A. and Wehrli B., 2006. Biogenic silica accumulation in the sediments of Iron Gate I Reservoir on the Danube River. Aquat. Sci., 68, 469-481.

Titman D. and Kilham P., 1976. Sinking in freshwater phytoplankton: some ecological implications of cell nutrient status and physical mixing processes. Limnol. Oceanogr., 21, 409-417.

Tomioka N., Imai A., and Komatsu K., 2011. Effect of light availability on Microcystis aeruginosa blooms in shallow hypereutrophic Lake Kasumigaura. J. Plankton Res., 33, $1263-1273$. 